\title{
USAGE OF THE MODIFIED VARIATIONAL ITERATION TECHNIQUE FOR SOLVING FREDHOLM INTEGRO-DIFFERENTIAL EQUATIONS
}

\author{
AHMED A. HAMOUD ${ }^{1,2}$, LAFTA A. DAWOOD ${ }^{3}$, \\ KIRTIWANT P. GHADLE ${ }^{2} \&$ SHAKIR M. ATSHAN ${ }^{3}$
}

${ }^{1}$ Department of Mathematics, Faculty of Education and Science, Taiz University, Taiz, Yemen

${ }^{2}$ Department of Mathematics, Dr. Babasaheb Ambedkar Marathwada University, Aurangabad, India

${ }^{3}$ Department of Mathematics, Thi Qar Directorates of Education, Ministry of Education, Iraq

\begin{abstract}
In this paper, we present a modified variational iteration method for solving Fredholm integro-differential equations. This study provides an analytical approximation to determine the behavior of the solution. Moreover, it proves the existence and uniqueness in results and convergence of the solution. Finally, some examples are included to demonstrate the validity and applicability of the proposed technique.

KEYWORDS: Modified Variational Iteration Method, Fredholm Integro-Differential Equation, Approximate Solution
\end{abstract}

Received: Feb 08, 2019; Accepted: Feb 28, 2019; Published: Apr 05, 2019; Paper Id.: IJMPERDAPR201987

\section{INTRODUCTION}

In recent years, there has been a growing interest in the integro-differential equations, which are a combination of differential and integral equations. The nonlinear Fredholm integro-differential equations play an important role in many branches of nonlinear functional analysis and their applications in the theory of engineering, mechanics, physics, electrostatics, biology, chemistry and economics [1-6,22-30]. In this paper, we consider the Fredholm integro-differential equations of the type:

$$
\sum_{j=0}^{k} \xi_{j}(x) Z^{(j)}(x)=f(x)+\gamma \int_{a}^{b} K(x, t) G(Z(t)) d t
$$

with the initial conditions

$$
Z^{(r)}(a)=b_{r}, \quad r=0,1,2, \ldots,(k-1)
$$

where $Z^{(j)}(x)$ is the $j^{\text {th }}$ derivative of the unknown function $Z(x)$ that will be determined, $K(x, t)$ is the kernel of the equation, $f(x)$ and $\xi_{j}(x)$ are an analytic function, $G$ is nonlinear function of $Z$ and $a, b, \gamma$, and $b$ are real finite constants. Recently, many authors focus on the development of numerical and analytical techniques for integrodifferential equations. For instance, we can remember the following works: Abbasbandy and Elyas [2] studied some applications on variational iteration method for solving system of nonlinear Volterra integro-differential equations, Hamoud and Ghadle [6] applied the hybrid methods for solving nonlinear Volterra-Fredholm integrodifferential equations, Alao et al. [4] used Adomian decomposition and variational iteration methods for solving integro-differential equations, Yang and Hou [21] applied the Laplace decomposition method to solve the 
fractional integro-differential equations, Mittal and Nigam [16] applied the Adomian decomposition method to approximate solutions for fractional integro-differential equations, and Behzadi et al. [5] solved some class of nonlinear Volterra-Fredholm integro-differential equations by homotopy analysis method. Moreover, several authors have applied the Adomian decomposition method and the variational iteration method to find the approximate solutions of various types of integro-differential equations [6, 9-11, 16, 21].

The main objective of the present paper is to study the behavior of the solution that can be formally determined by semi-analytical approximated method as the variational iteration method. Moreover, we proved the existence, uniqueness results and convergence of the solutions of the Fredholm integro-differential equation (1.1).

\section{DESCRIPTION OF THE METHOD}

Some powerful methods have been focusing on the development of more advanced and efficient methods for integro-differential equations such as the variational iteration method $[2,4,13,15]$. We will describe this method in this section:

\subsection{Modified Variational Iteration Method (MVIM)}

MVIM is applied to solve a large class of linear and nonlinear problems with approximations converging rapidly to exact solutions. The main idea of this method is to construct a correction functional form using general Lagrange multipliers. These multipliers should be chosen such that its correction solution is superior to its initial approximation, called trial function. It is the best within the flexibility of trial functions. Accordingly, Lagrange multipliers can be identified by the variational theory [17-19]. A complete review of He's variational iteration method is available in [13, 15]. The initial approximation can be freely chosen with possible unknowns, which can be determined by imposing boundary/initial conditions. To illustrate, we consider the following general differential equation:

$$
\mathrm{LZ}(\mathrm{x})+\mathrm{NZ}(\mathrm{x})=\mathrm{f}(\mathrm{x}),
$$

Where, $L$ is a linear operator, $N$ is a nonlinear operator and $f(x)$ is inhomogeneous term. According to variational iteration method [4], the terms of a sequence $Z_{n}$ are constructed such that this sequence converges to the exact solution. The terms $Z_{n}$ are calculated by a correction functional as follows:

$$
Z_{n+1}(x)=Z_{n}(x)+\int_{0}^{x} \lambda(\tau)\left(L Z_{n}(\tau)+N \tilde{y}(\tau)-f(\tau)\right) d \tau .
$$

The successive approximation $\mathrm{Z}_{\mathrm{n}}(\mathrm{x}), \mathrm{n} \geq 0$ of the solution $\mathrm{Z}(\mathrm{x})$ will be readily obtained upon using the obtained Lagrange multiplier, and by using any selective function $Z_{0}$. The zeroth approximation $Z_{0}$ may be selected using any function that just satisfies at least the initial and boundary conditions, with $\lambda$ determined, several approximations $Z_{n}(x), n \geq$ 0 follow immediately.

The VIM has been shown to solve effectively, easily and accurately a large class of nonlinear problems with approximations converging rapidly to accurate solutions.

To obtain the approximation solution of IVB (1.1) - (1.2), according to the VIM, the iteration formula (2.2) can be written as follows.

$$
Z_{n+1}(x)=Z_{n}(x)+L^{-1}\left[\lambda(x)\left[\sum_{j=0}^{k} \xi_{j}(x) Z_{n}^{(j)}(x)-f(x)-\gamma \int_{a}^{b} K(x, t) G\left(Z_{n}(t)\right) d t\right]\right],
$$


where $L^{-1}$ is the multiple integration operator given as follows:

$L^{-1}(\cdot)=\int_{a}^{b} \int_{a}^{b} \ldots \int_{a}^{b}(\cdot) d x d x \ldots d x(k-$ times $)$

To find the optimal $\lambda(x)$, we proceed as follows:

$$
\begin{aligned}
& \delta Z_{n+1}(x)=\delta Z_{n}(x)+\delta L^{-1}\left[\lambda(x)\left[\sum_{j=0}^{k} \xi_{j}(x) Z_{n}^{(j)}(x)-f(x)-\gamma \int_{a}^{b} K(x, t) G\left(Z_{n}(t)\right) d t\right]\right] \\
& =\delta Z_{n}(x)+\lambda(x) \delta Z_{n}(x)-L^{-1}\left[\delta Z_{n}(x) \lambda^{\prime}(x)\right] .
\end{aligned}
$$

From Equation (2.3), the stationary conditions can be obtained as follows,

$$
\lambda^{\prime}(x)=0, \text { and } 1+\left.\lambda(x)\right|_{x=t}=0 .
$$

As a result, the Lagrange multipliers can be identified as $\lambda(x)=-1$ and by substituting in Equation (2.3), the following iteration formula is obtained.

$$
\begin{aligned}
& Z_{0}(x)=L^{-1}\left[\frac{f(x)}{\xi_{k}(x)}\right]+\sum_{r=0}^{k-1} \frac{(x-a)^{r}}{r !} b_{r}, \\
& Z_{n+1}(x)=Z_{n}(x)-L^{-1}\left[\sum_{j=0}^{k} \xi_{j}(x) Z_{n}^{(j)}(x)-f(x)-\gamma \int_{a}^{b} K(x, t) G\left(Z_{n}(t)\right) d t\right], n \geq 0 .
\end{aligned}
$$

The term $\sum_{r=0}^{k-1} \frac{(x-a)^{r}}{r !} b_{r}$ is obtained from the initial conditions, $\xi_{k}(x) \neq 0$. Relation (2.4) will enable us to determine the components $Z_{n}(x)$ recursively for $n \geq 0$. Consequently, the approximation solution may be obtained by using

$$
Z(t)=\lim _{n \rightarrow \infty} Z_{n}(t)
$$

\section{MAIN RESULTS}

In this section, we shall give an existence and uniqueness results of Equation (1.1), with the initial condition (1.2) and prove it [6-8]. We can write the equation (1.1) in the form of:

$$
Z(x)=L^{-1}\left[\frac{f(x)}{\xi_{k}(x)}\right]+\sum_{r=0}^{k-1} \frac{(x-a)^{r}}{r !} b_{r}+\gamma L^{-1}\left[\int_{a}^{b} \frac{1}{\xi_{k}(x)} K(x, t) G\left(Z_{n}(t)\right) d t\right]-L^{-1}\left[\sum_{j=0}^{k-1} \frac{\xi_{j}(x)}{\xi_{k}(x)} Z^{(j)}(x)\right]
$$

Such that,

$$
\begin{aligned}
& L^{-1}\left[\int_{a}^{b} \frac{1}{\xi_{k}(x)} K(x, t) G\left(Z_{n}(t)\right) d t\right]=\int_{a}^{b} \frac{(x-t)^{k}}{k ! \xi_{k}(x)} K(x, t) G\left(Z_{n}(t)\right) d t \\
& \sum_{j=0}^{k-1} L^{-1}\left[\frac{\xi_{j}(x)}{\xi_{k}(x)}\right] Z^{(j)}(x)=\sum_{j=0}^{k-1} \int_{a}^{b} \frac{(x-t)^{k-1} \xi_{j}(t)}{k-1 ! \xi_{k}(t)} Z^{(j)}(t) d t .
\end{aligned}
$$

We set, 
$\Psi(x)=L^{-1}\left[\frac{f(x)}{\xi_{k}(x)}\right]+\sum_{r=0}^{k-1} \frac{(x-a)^{r}}{r !} b_{r}$.

Before starting and proving the main results, we introduce the following hypotheses:

(H1)There exist two constants $\alpha$ and $\gamma_{j}>0, j=0, \ldots, k$ such that, for any $Z_{1}, Z_{2} \in C(J, \square)$.

$\left.\left.\mid G\left(Z_{1}\right)\right)-G\left(Z_{2}\right)\right)|\leq \alpha| Z_{1}-Z_{2} \mid$

and

$\left|D^{j}\left(Z_{1}\right)-D^{j}\left(Z_{2}\right)\right| \leq \gamma_{j}\left|Z_{1}-Z_{2}\right|$

We suppose that the nonlinear terms $G(Z(x))$ and $D^{\prime}(Z)=\left(\frac{d^{\prime}}{d x^{\prime}}\right) Z(x)=\sum_{i=0}^{\infty} \gamma_{i}, \quad\left(D^{j}\right.$ is a derivative operator), $j=0,1, \ldots, k$, are Lipschitz continuous.

(H2)We suppose that for all $a \leq t \leq x \leq b$, and $j=0,1, \ldots, k$,

$\left|\frac{\gamma(x-t)^{k} K(x, t)}{k ! \xi_{k}(x)}\right| \leq \theta_{1}, \quad\left|\frac{\gamma(x-t)^{k} K(x, t)}{k !}\right| \leq \theta_{2}$,

$\left|\frac{(x-t)^{k-1} \xi_{j}(t)}{(k-1) ! \xi_{k}(t)}\right| \leq \theta_{3}, \quad\left|\frac{(x-t)^{k-1} \xi_{j}(t)}{(k-1) !}\right| \leq \theta_{4}$.

(H3)There exist three functions $\theta_{3}^{*}, \theta_{4}^{*}$, and $\gamma^{*} \in C\left(D, \square^{+}\right)$, the set of all positive function continuous on $D=\{(x, t) \in \square \times \square: 0 \leq t \leq x \leq 1\}$ such that:

$\theta_{3}^{*}=\max \left|\theta_{3}\right|, \theta_{4}^{*}=\max \left|\theta_{4}\right|$, and $\gamma^{*}=\max \left|\gamma_{j}\right|$.

(H4) $\Psi(x)$ is bounded function for all $x$ in $J=[a, b]$.

Theorem 3.1. Assume that (H1)-(H4) hold. If

$0<\psi=\left(\alpha \theta_{1}+k \gamma^{*} \theta_{3}^{*}\right)(b-a)<1$.

Then, there exists a unique solution $Z(x) \in C(J)$ to IVB (1.1) - (1.2).

Proof.

Let $Z_{1}$ and $Z_{2}$ be two different solutions of IVB (1.1) - (1.2), then

$$
\begin{aligned}
& \left.\left.\left|Z_{1}-Z_{2}\right|=\mid \int_{a}^{b} \frac{\gamma(x-t)^{k} K(x, t)}{\xi_{k}(x) k !}\left[G\left(Z_{1}\right)-G\left(Z_{2}\right)\right)\right] d t-\sum_{j=0}^{k-1} \int_{a}^{b} \frac{(x-t)^{k-1} \xi_{j}(t)}{\xi_{k}(t)(k-1) !}\left[D^{j}\left(Z_{1}\right)-D^{j}\left(Z_{2}\right)\right)\right] d t \mid \\
& \left.\left.\leq \int_{a}^{b} \mid \frac{\gamma(x-t)^{k} K(x, t)}{\xi_{k}(x) k !} \| G\left(Z_{1}\right)-G\left(Z_{2}\right)\right)\left|d t-\sum_{j=0}^{k-1} \int_{a}^{b}\right| \frac{(x-t)^{k-1} \xi_{j}(t)}{\xi_{k}(t)(k-1) !} \| D^{j}\left(Z_{1}\right)-D^{j}\left(Z_{2}\right)\right) \mid d t \\
& \leq\left(\alpha \theta_{1}+k \gamma^{*} \theta_{3}^{*}\right)(b-a)\left|Z_{1}-Z_{2}\right|,
\end{aligned}
$$


we get $(1-\psi)\left|Z_{1}-Z_{2}\right| \leq 0$. Since $0<\psi<1$, so $\left|Z_{1}-Z_{2}\right|=0$. therefore, $Z_{1}=Z_{2}$ and the proof is completed.

Theorem 3.2. If problem (1.1) - (1.2) has a unique solution, then the solution $Z_{n}(x)$ obtained from the recursive relation (2.4) using VIM converges when

$0<\phi=\left(\alpha \theta_{2}+k \gamma^{*} \theta_{4}^{*}\right)(b-a)<1$.

Proof. We have from equation (2.4):

$Z_{n+1}(x)-Z(x)=Z_{n}(x)-Z(x)-\left(L^{-1}\left[\sum^{k} \xi_{j}(x)\left[Z_{n}^{(j)}(x)-Z^{(j)}(x)\right]\right]-L^{-1}\left[\gamma \int_{a}^{b} K(x, t)\left[G\left(Z_{n}(t)\right)-G(Z(t))\right] d t\right]\right)$.

If we set, $\xi_{k}(x)=1$, and $W_{n+1}(x)=Z_{n+1}(x)-Z(x), W_{n}(x)=Z_{n}(x)-Z(x)$ since $W_{n}(a)=0$, then $W_{n+1}(x)=W_{n}(x)+\int_{a}^{b} \frac{\gamma K(x, t)(x-t)^{k}}{k !}\left[G\left(Z_{n}(t)\right)-G(Z(t))\right] d t-\sum_{j=0}^{k-1} \int_{a}^{b} \frac{\lambda_{1} \xi_{j}(t)(x-t)^{k-1}}{(k-1) !}\left[D^{j}\left(Z_{n}(t)\right)-D^{j}(Z(t))\right] d t-\left(W_{n}(x)-W_{n}(a)\right)$.

Therefore,

$\left|W_{n+1}(x)\right| \leq \int_{a}^{b}\left|\frac{\gamma K(x, t)(x-t)^{k}}{k !}\right|\left|W_{n}\right| \alpha d t+\sum_{j=0}^{k-1} \int_{a}^{b}\left|\frac{\gamma \xi_{j}(t)(x-t)^{k-1}}{(k-1) !}\right| \max \left|\gamma_{j} \| W_{n}\right| d t$

$\leq\left|W_{n}\right|\left[\int_{a}^{b} \alpha \theta_{2} d t+\sum_{j=0}^{k-1} \int_{a}^{b} \theta_{4}^{*}|\max | \gamma_{j} \mid\right.$

$\leq\left|W_{n}\right|\left(\alpha \theta_{2}+k \gamma^{*} \theta_{4}^{*}\right)(b-a)=\left|W_{n}\right| \phi$.

Hence,

$\left\|W_{n+1}\right\|=\max _{\forall x \in J}\left|W_{n+1}(x)\right|$

$\leq \phi \max _{\forall x \in J}\left|W_{n}(x)\right|$

$=\phi\left\|W_{n}\right\|$.

Since $0<\phi<1$, then $\left\|W_{n}\right\| \rightarrow 0$. So, the series converges and the proof is complete.

\section{NUMERICAL RESULTS}

In this section, we present the semi-analytical technique based on the VIM to solve Fredholm integro-differential equations. To show the efficiency of the present method for our problems in comparison with the exact solution, we report absolute error.

Example 1. Consider the following Fredholm integro-differential equation.

$Z^{\prime}(x)=e^{x}-x+x e^{x}+\int_{0}^{1} x Z(s) d s$,

with the initial condition

$Z(0)=0$,

and the exact solution is $Z(x)=x e^{x}$. 
Table 1: Numerical Results of the Example 1

\begin{tabular}{|c|c|c|c|}
\hline $\mathbf{x}$ & Exact Solution & MVIM & $\mathbf{E r}_{\text {MVIM }}$ \\
\hline 0.1 & 0.1105170918 & 0.1105170888 & $3.00 \times 10^{-9}$ \\
\hline 0.2 & 0.2442805516 & 0.2442805506 & $1.00 \times 10^{-9}$ \\
\hline 0.3 & 0.4049576424 & 0.4049576457 & $2.80 \times 10^{-9}$ \\
\hline 0.4 & 0.5967298792 & 0.5967298865 & $7.30 \times 10^{-9}$ \\
\hline 0.5 & 0.8243606355 & 0.8243606264 & $9.10 \times 10^{-9}$ \\
\hline 0.6 & 1.0932712800 & 1.0932712700 & $1.00 \times 10^{-8}$ \\
\hline 0.7 & 1.4096268950 & 1.4096267890 & $1.06 \times 10^{-7}$ \\
\hline 0.8 & 1.7804327420 & 1.7804325720 & $1.70 \times 10^{-7}$ \\
\hline 0.9 & 2.2136428000 & 2.2136429590 & $1.59 \times 10^{-7}$ \\
\hline 1.0 & 2.7182818280 & 2.7182818230 & $5.00 \times 10^{-9}$ \\
\hline
\end{tabular}

Example 2. Consider the following Fredholm integro-differential equation.

$Z^{\prime}(x)=\frac{5}{4}-\frac{x^{2}}{2}+\int_{0}^{1}\left(x^{2}-s\right) Z^{2}(s) d s$,

with the initial condition

$Z(0)=0$,

and the exact solution is

$Z(x)=x$

Table 2: Numerical Results of the Example 2

\begin{tabular}{|c|c|c|c|}
\hline $\mathbf{x}$ & Exact Solution & MVIM & Er $_{\text {MVIM }}$ \\
\hline 0.1 & 0.10000 & 0.09987 & $1.3 \times 10^{-4}$ \\
\hline 0.2 & 0.20000 & 0.19974 & $2.6 \times 10^{-4}$ \\
\hline 0.3 & 0.30000 & 0.29962 & $3.8 \times 10^{-4}$ \\
\hline 0.4 & 0.40000 & 0.39951 & $4.9 \times 10^{-4}$ \\
\hline 0.5 & 0.50000 & 0.49941 & $5.9 \times 10^{-4}$ \\
\hline 0.6 & 0.60000 & 0.59934 & $6.6 \times 10^{-4}$ \\
\hline 0.7 & 0.70000 & 0.69928 & $7.2 \times 10^{-4}$ \\
\hline 0.8 & 0.80000 & 0.79925 & $7.5 \times 10^{-4}$ \\
\hline 0.9 & 0.90000 & 0.89926 & $7.4 \times 10^{-4}$ \\
\hline 1.0 & 1.00000 & 0.99929 & $7.1 \times 10^{-4}$ \\
\hline
\end{tabular}

\section{CONCLUSIONS}

We present the MVIM for solving Fredholm integro-differential equations. From the computational viewpoint, the MVIM is more efficient, convenient and easy to use. The method is very powerful and efficient in finding analytical as well as numerical solutions for wide classes of linear and nonlinear Fredholm integro-differential equations. Moreover, we proved the existence and uniqueness results and convergence of the solution. The convergence theorem and the numerical results establish the precision and efficiency of the proposed technique.

\section{ACKNOWLEDGMENTS}

The authors would like to thank the anonymous reviewers and the editor of this journal for their helpful comments and valuable suggestions, which led to an improved presentation of this paper. 


\section{REFERENCES}

1. Hamoud, A.A. and Ghadle, K.P. Modified variational iteration method for solving Caputo fractional Volterra-Fredholm integro-differential equations, International Journal of Mathematics and Computation, 30(2) (2019), 13-25.

2. Abbasbandy, S. and Elyas, S. Application of variational iteration method for system of nonlinear Volterra integro-differential equations, Mathematics and computational applications, 2(14) (2009), 147-158.

3. Hamoud, A.A., Azeez, A.D. and Ghadle, K.P. A study of some iterative methods for solving fuzzy Volterra-Fredholm integral equations, Indonesian J. Elec. Eng. \& Comp. Sci.11(3) (2018), 1228-1235.

4. Alao, S. Akinborol, F. Akinpelu, F. and Oderinu, R. Numerical solution of integro-differential equation using Adomian decomposition and variational iteration methods, IOSR Journal of Mathematics, 10(4) (2014), 18-22.

5. Behzadi, S. Abbasbandy, S. Allahviranloo, T. and Yildirim, A. Application of homotopy analysis method for solving a class of nonlinear Volterra-Fredholm integro-differential equations, J. Appl. Anal. Comput. 2(2) (2012), 127-136.

6. Hamoud, A.A. and Ghadle, K.P. The approximate solutions of fractional Volterra-Fredholm integro-differential equations by using analytical techniques, Probl. Anal. Issues Anal., 7(25) (2018), 41-58.

7. Burton, T.A. Integro-differential equations, compact maps, positive kernels, and Schaefer's fixed point theorem, Nonlinear Dyn. Syst. Theory, 17(1) (2017), 19-28.

8. Burton, T.A. Existence and uniqueness results by progressive contractions for integro-differential equations, Nonlinear Dyn. Syst. Theory, 16(4) (2016), 366-371.

9. Hamoud, A.A. and Ghadle, K.P. The reliable modified of Laplace Adomian decomposition method to solve nonlinear interval Volterra-Fredholm integral equations, Korean J. Math. 25(3) (2017), 323-334.

10. Hamoud, A.A., Ghadle, K.P., Banilssa, M.SH. and Giniswamy, Existence and uniqueness theorems for fractional VolterraFredholm integro-differential equations, Int. J. Appl. Math. 31(3) (2018), 333-348.

11. Hamoud, A.A. and Ghadle, K.P. Modified Adomian decomposition method for solving fuzzy Volterra-Fredholm integral equations, J. Indian Math. Soc. 85(1-2) (2018), 52-69.

12. Gajalakshmi, S., \& Parvathi, P. Solving an EOQ Model in an Inventory Problem by using Octagonal Fuzzy Numbers.

13. He, J.H. A variational approach to nonlinear problems and its application, Mech. Applic. 20(1) (1998), 30-34.

14. Abed, S. S., \& Abbas, R. F. (2016). S-iteration for general quasi multi valued contraction mappings. Int. J. Appl. Math. Stat. Sci, 5(4), 9-22.

15. He, J.H. and Wang, S.Q. Variational iteration method for solving integro-differential equations, Phys. Lett. A367 (2007), 188191.

16. Mittal, R. and Nigam, R. Solution of fractional integro-differential equations by Adomian decomposition method, Int. J. Appl. Math. Mech., 4(2) (2008), 87-94.

17. Wazwaz, A.M. A comparison between variational iteration method and Adomian decomposition method, Journal of computational and applied Mathematics, 207 (2007), 129-136.

18. Wazwaz, A.M. The variational iteration method for solving linear and non-linear Volterra integral and integro-differential equations, Int. J. Comput. Math. 87(5) (2010), 1131-1141.

19. Wazwaz, A.M. Linear and Nonlinear Integral Equations Methods and Applications, Springer Heidelberg Dordrecht London New York, 2011. 
20. El-Sheikh, M. M. A., Sallam, R. A., \& Nahed, M. M. New criteria for oscillation of second order nonlinear dynamic equations with damping on time scales. IJRANSS, 3, 79-86.

21. Yang, C. and Hou, J. Numerical solution of integro-differential equations of fractional order by Laplace decomposition method, Wseas Trans. Math., 12(12) (2013), 1173-1183.

22. Hamoud, A.A. and Ghadle, K.P. Some new existence, uniqueness and convergence results for fractional Volterra-Fredholm integro-differential equations, J. Appl. Comput. Mech., 5(1), (2019), 58-69.

23. Safarabadi, M., Mohammadi, M., Farajpour, A. and Goodarzi, M. Effect of surface energy on the vibration analysis of rotating nanobeam. Journal of Solid Mechanics, 7(3), (2015), 299-311.

24. Hamoud, A.A., BaniIssa, M.SH .and Ghadle, K.P. Existence and uniqueness results for nonlinear Volterra-Fredholm integrodifferential equations, Nonlinear Functional Analysis and Applications, 23(4), (2018), 797-805.

25. Hamoud, A.A. and Ghadle, K.P. Existence and uniqueness of the solution for Volterra- Fredholm integro-differential equations, Journal of Siberian Federal University. Mathematics \& Physics, 11(6), (2018), 692-701.

26. Hamoud, A.A. and Ghadle, K.P. Homotopy analysis method for the first order fuzzy Volterra-Fredholm integro-differential equations, Indonesian J. Elec. Eng. \& Comp. Sci.11(3) (2018), 857-867.

27. Hamoud, A.A. and Ghadle, K.P. Existence and uniqueness of solutions for fractional mixed Volterra-Fredholm integrodifferential equations, Indian J. Math., 60(3), (2018), 375-395.

28. Hamoud, A.A. and Ghadle, K.P. Usage of the homotopy analysis method for solving fractional Volterra-Fredholm integrodifferential equation of the second kind, Tamkang Journal of Mathematics, 49(4), (2018), 301-315.

29. Ghadle, K.P., Hamoud, A.A. and Banilssa M.SH. A comparative study of variational iteration and Adomian decomposition techniques for solving Volterraintegro-differential equations, International Journal of Mathematics Trends and Technology, ICETST. (2018), 16-21.

30. Hamoud, A.A., Ghadle, K.P. and Atshan, S.M. The approximate solutions of fractional integro-differential equations by using modified Adomian decomposition method, Khayyam J. Math. 5(1), (2019), 21-39. 